\title{
PER1 prevents excessive innate immune response during endotoxin-induced liver injury through regulation of macrophage recruitment in mice
}

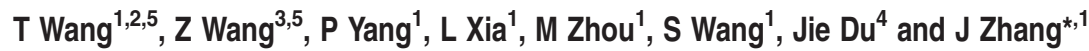

The severity of acute liver failure (ALF) induced by bacterial lipopolysaccharide (LPS) is associated with the hepatic innate immune response. The core circadian molecular clock modulates the innate immune response by controlling rhythmic pathogen recognition by the innate immune system and daily variations in cytokine gene expression. However, the molecular link between circadian genes and the innate immune system has remained unclear. Here, we showed that mice lacking the clock gene Per1 (Period1) are more susceptible to LPS/D-galactosamine (LPS/GalN)-induced macrophage-dependent ALF compared with wild-type (WT) mice. Per1 deletion caused a remarkable increase in the number of Kupffer cells (KCs) in the liver, resulting in an elevation of the levels of pro-inflammatory cytokines after LPS treatment. Loss of Per1 had no effect on the proliferation or apoptosis of macrophages; however, it enhanced the recruitment of macrophages, which was associated with an increase in CC chemokine receptor 2 (Ccr2) expression levels in monocytes/macrophages. Deletion of Ccr2 rescued D-GalN/LPS-induced liver injury in $\mathrm{Per}^{-1-}$ mice. We demonstrated that the upregulation of Ccr2 expression by Per1 deletion could be reversed by the synthetic peroxisome proliferator-activated receptor gamma (PPAR- $\gamma$ ) antagonist GW9662. Further analysis indicated that PER1 binds to PPAR- $\gamma$ on the Ccr2 promoter and enhanced the inhibitory effect of PPAR- $\gamma$ on Ccr2 expression. These results reveal that Per1 reduces hepatic macrophage recruitment through interaction with PPAR- $\gamma$ and prevents an excessive innate immune response in endotoxin-induced liver injury.

Cell Death and Disease (2016) 7, e2176; doi:10.1038/cddis.2016.9; published online 7 April 2016

Acute liver failure (ALF) is characterized by severe hepatic injury with failure of hepatocyte function, resulting in a clinical syndrome of coagulopathy, encephalopathy and circulatory dysfunction. ALF is associated with high overall mortality, ranging from 30 to $80 \%$. ${ }^{1}$ Bacterial lipopolysaccharide (LPS) is implicated in the pathogenesis of ALF. LPS enters the liver through the portal blood flow and promotes the hepatic innate immune response. As key components of the hepatic innate immune system, Kupffer cells (KCs) are postulated to have a central role in response to LPS. Upon stimulation by LPS, KCs secrete pro-inflammatory cytokines, including interleukin 1 (IL-1), IL-6, monocyte chemoattractant protein 1 (MCP-1) and tumor necrosis factor (TNF)- $a$. Many of these proinflammatory mediators can trigger hepatocyte cell death and lead to $\mathrm{ALF}^{2,3}$

Recent studies in mice demonstrated that the actions of macrophages in ALF largely depend on the recruitment of monocytes and macrophages into the liver. ${ }^{4,5}$ Chemokines may be critically involved in this process of leukocyte recruitment and activation. Leukocytes sense concentration gradients and move toward increasing chemokine concentrations. One of the most potent chemokines identified for monocytes and macrophages is MCP-1, which acts by binding to the $\mathrm{CC}$ chemokine receptor 2 (CCR2). Evidence from both murine and human studies suggests that CCR2/ MCP-1 chemotaxis is responsible for the mobilization and subsequent trafficking of a population of activated monocytes/ macrophages to the liver from the bone marrow. ${ }^{6-8}$

Circadian rhythms are reflected by daily oscillations of multiple biological processes including the immune response. The fundamental mechanism of rhythm generation is highly conserved. Interlocked transcriptional/translational feedback loops involving clock genes, such as Per1-3, Cry1-2, Clock, Bmal1 and Rev-Erba, create oscillations on the molecular level. ${ }^{9,10}$ In mice, significant temporal dependence of LPSinduced endotoxic shock has been reported. ${ }^{11}$ The nuclear receptor Rev-Erba mediates selective circadian regulation of inflammatory cytokines. ${ }^{12}$ Innate immune pathogen recognition mechanisms are also under circadian control. The circadian clock controls Toll-like receptor 9-mediated innate and adaptive immunity. ${ }^{13}$ Blood leukocyte numbers have long been known to exhibit circadian oscillations. ${ }^{14,15}$ Recent

\footnotetext{
${ }^{1}$ Center for Molecular Metabolism, Nanjing University of Science and Technology, Nanjing, China; ${ }^{2}$ Cambridge Suda Genome Resource Center, Soochow University, Suzhou, China; ${ }^{3}$ Department of Radiology, Affiliated Hospital of Nanjing University of Chinese Medicine, Nanjing, China and ${ }^{4}$ Beijing An Zhen Hospital, Capital Medical University, Beijing, China

${ }^{*}$ Corresponding author: J Zhang, Center for Molecular Metabolism, Nanjing University of Science and Technology, B508, No. 364 Building, 200 Xiaolinwei Street, Nanjing 210094, China. Tel/Fax: +86 258431 8533; E-mail: jfzhang @mail.njust.edu.cn

${ }^{5}$ These authors contributed equally to this work.

Abbreviations: Per1, Period1; GalN, galactosamine; LPS, lipopolysaccharide; CCR2, CC chemokine receptor 2; IP, immunoprecipitation; PPAR- $\gamma$, peroxisome proliferator-activated receptor gamma; ALF, acute liver failure; KCs, Kupffer cells; MCP-1, monocyte chemoattractant protein 1; WT, wild-type; TNF, tumor necrosis factor; IL, interleukin; RT, reverse transcriptase

Received 10.10.15; revised 06.1.16; accepted 07.1.16; Edited by H-U Simon
} 
studies have revealed that gene expression in macrophages exhibits robust circadian oscillation. ${ }^{16}$

Given the intimate association between the innate immune response and circadian rhythms, we explored the role of the clock gene Per1 (Period1) in ALF induced by administration of D-galactosamine (GalN)/LPS, which is a well-established model similar to ALF in the clinical setting. The results presented here showed that $\mathrm{Per1}^{-1-}$ mice develop more severe D-GalN/LPS-induced inflammatory liver damage, as evidenced by increased production of pro-inflammatory cytokines, as well as more severe liver pathology. The hepatic recruitment of macrophages was enhanced in $P e r 1^{-/-}$mice, which leads to increased susceptibility to D-GalN/LPS. We further demonstrated that deletion of Per1 alleviates the inhibitory effect of peroxisome proliferator-activated receptor gamma (PPAR- $\gamma$ ) on Ccr2 expression, resulting in an increase in the number of KCs in $\mathrm{Per1}^{-1-}$ mice.

\section{Results}

Loss of Per1 leads to an increase in D-GalN/LPS-induced lethality. To examine the effects of Per1 loss on the inflammatory response, mice were injected intraperitoneally with LPS in combination with D-GalN. In the Per1-/- mice group, mortality became apparent at 5-6 h, and all mice died by $10 \mathrm{~h}$. In the wild-type (WT) mice group, no death was observed at $6 \mathrm{~h}$; the first animal death was observed at $8 \mathrm{~h}$, and the survival rate was $60 \%$ at $24 \mathrm{~h}$ (Figure 1a). Based on the survival rate, additional WT and $P e r 1^{-1-}$ mice were killed $5 \mathrm{~h}$ after D-GalN/LPS administration to obtain blood samples and liver tissues for liver enzyme and tissue analyses. Serum alanine transaminase (ALT) and aspartate transaminase (AST) activities were found to be significantly higher in $\mathrm{Per1}^{-1-}$ mice than that in WT mice (Figure 1b). Histological examination of the liver tissues revealed more prominent liver damage in $\mathrm{Per}^{-/-}$mice (Figure 1c). In the Per1 ${ }^{-1-}$ mice group, massive hemorrhagic necrosis and hepatocyte apoptosis were observed, with prominent vascular congestion and inflammatory cell infiltration. In contrast, liver damage and histological changes were found to be significantly less severe in WT mice. Then, we explored the impact of Per1 on non-lethal liver inflammation induced by D-GalN/LPS treatment. The results showed that none of the WT mice treated with $3 \mu \mathrm{g} / \mathrm{kg}$ LPS and $200 \mathrm{mg} / \mathrm{kg}$ D-GalN died. Administration of D-GalN/LPS at this lower dosage caused no apparent liver injury in WT mice. In Per1 ${ }^{-1-}$ mice, the same dose of D-GalN/ LPS induced significant liver injury, as detected by increased transaminase activities and histological changes (Figures 1d and e).

Loss of Per1 increases D-GalN/LPS-induced production of inflammatory cytokines and chemokines. Current models of D-GalN/LPS have associated outcomes with elevated production of inflammatory cytokines; thus, we measured the levels of serum cytokines in mice after D-GaIN/LPS administration. Serum TNF- $a$, IL- $1 \beta$ and IL- 6 were significantly higher in $P e r 1^{-1-}$ mice than in WT mice (Figure 2a). Real-time reverse transcriptase (RT)-PCR analysis of TNF- $a$, IL- $1 \beta$, IL- 6 and MCP-1 (Figures $2 b-e$ ) revealed that the expression of all these cytokines was markedly elevated in the Per1 ${ }^{-/-}$mice either with or without D-GalN/LPS treatment.

Loss of Per1 increases the number of $\mathrm{KCs}$ in the liver. We then examined the response of $\mathrm{Per}^{-/}$cells to LPS. Peritoneal macrophages were isolated from WT and $P e r 1^{-1-}$ mice and stimulated with LPS $(1 \mu \mathrm{g} / \mathrm{ml})$. The expression of cytokines in macrophages was measured by real-time RT-PCR at $3 \mathrm{~h}$ after stimulation. Unexpectedly, Per1 deletion had no influence on the expression of any of the cytokines (Supplementary Figure S1). To confirm the phenotypes observed here, RAW264.7 cells were transfected with a plasmid expressing Per1 by electroporation as described previously. ${ }^{17}$ However, no changes in LPSinduced cytokine production were observed in either of the groups (Supplementary Figure S1). We next determined the number of KCs in the livers of $\mathrm{Per1}^{-1-}$ and WT mice. Administration of D-GalN/LPS significantly increased the number of $\mathrm{KCs}$ in both genotypes. Either under baseline conditions or after D-GaIN/LPS challenge, a marked increase was observed in the number of KCs in the livers of Per1 ${ }^{-/-}$ mice compared with the livers of WT mice, as shown by immunohistochemistry using a specific antibody against the KC marker genes F4/80 and CD68 (Figures 3a and b), as well as by the increased hepatic expression of F4/80 and CD68 (Figures $3 \mathrm{c}$ and d). We further used flow cytometry to identify specific populations of myeloid cells in the mouse liver. The data showed a significant increase in total $\mathrm{F} 4 / 80^{+}$ cells in untreated and treated $\mathrm{Per}^{-1-}$ mice (Figure $3 \mathrm{e}$ ). $\mathrm{F} 4 / 80^{+} \mathrm{CD}_{11 \mathrm{~b}^{+}}$cells showed a strong capacity for the production of cytokines in response to LPS. ${ }^{18}$ The relative number of these cells also increased in $\mathrm{Per}^{-1-}$ mice, either under baseline conditions or after D-GalN/LPS treatment (Figure $3 e$ ). These results implied that the increase in the number of $\mathrm{KCs}$ in $P e r 1^{-1}$ livers may contribute to the immune response to LPS and to increased hepatic cytokine production.

Per1 had no influence on the proliferation or apoptosis of macrophages. The increased number of macrophages in Per1-deficient livers could be the result of enhanced proliferation and/or impaired apoptosis of macrophages. Local production of M-CSF in the liver has a crucial role in the proliferation and maturation of KCs. ${ }^{19}$ We found that Per1 deficiency did not significantly change the hepatic expression of M-CSF (Supplementary Figure S2A). A cell cycle analysis of peritoneal macrophages isolated from WT and Per1 ${ }^{-1-}$ mice revealed similar numbers of macrophages undergoing the G0/G1, S and G2/M phases of the cell cycle (Supplementary Figure S2). An annexin V/PI assay was performed on macrophages harvested at 2, 4, 7 and 12 days of culture under routine conditions to assess the percentage of early apoptotic (annexin $\mathrm{V}+\mathrm{PI}-$ ) and late apoptotic/ necrotic (annexin $\mathrm{V}+/ \mathrm{PI}+$ ) cells. The WT and Per1-deficient macrophages displayed similar changes over time (Supplementary Figure S2). Therefore, we concluded that Per1 has no influence on the proliferation or apoptosis of macrophages. 

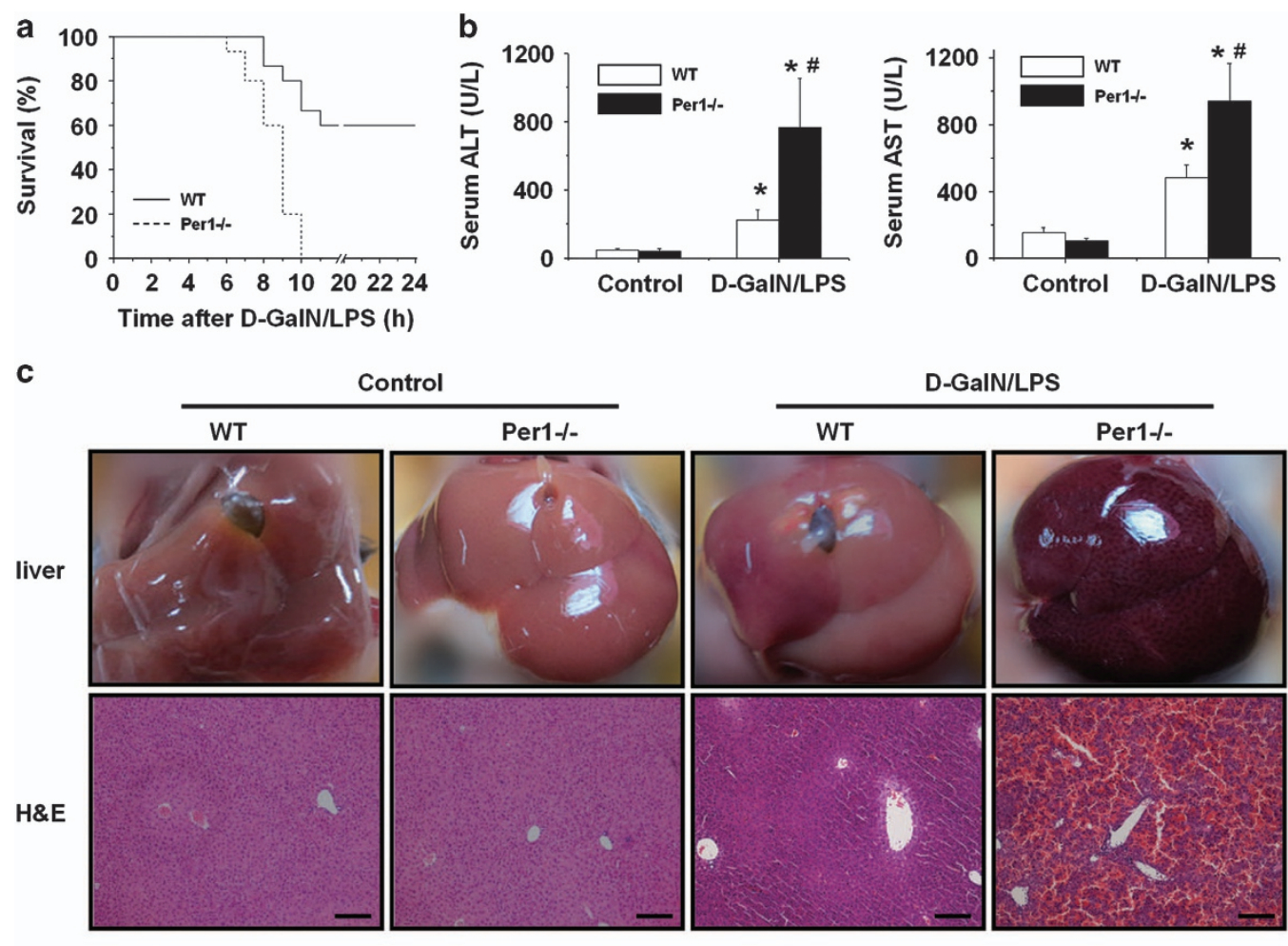

Control
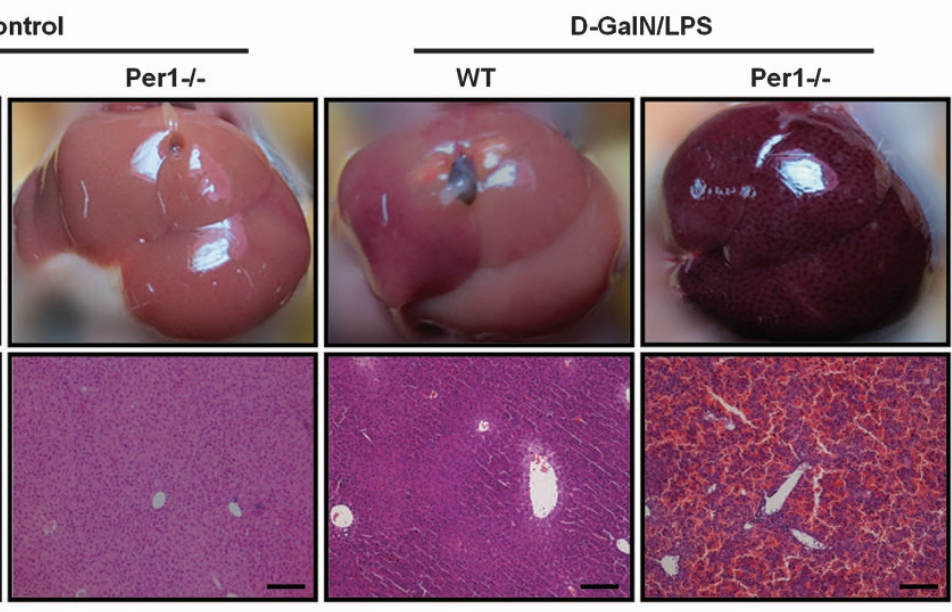

d
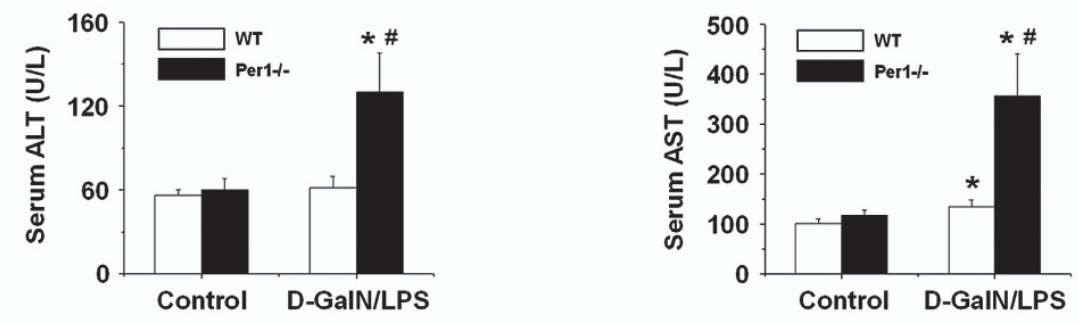

e

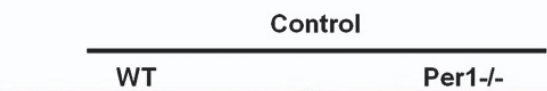

D-GaIN/LPS
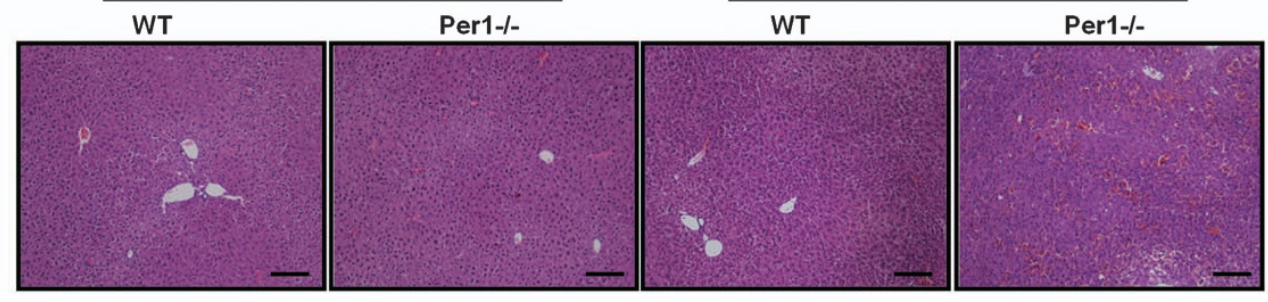

Figure 1 Per1 protects mice from D-GalN/LPS-induced liver injury and prolongs survival. WTand Per ${ }^{-1-}$ mice were administered $5 \mu \mathrm{g} / \mathrm{kg}$ body weight LPS intraperitoneally in combination with $500 \mathrm{mg} / \mathrm{kg}$ body weight D-GalN or PBS as the control. (a) Survival was monitored for $24 \mathrm{~h}$ ( $n=15$ for each group). (b) Serum activities of ALT and AST were measured $5 \mathrm{~h}$ after $\mathrm{D}$-GalN/LPS challenge. (c) Macroscopic appearance of representative liver samples and H\&E staining of the different groups (as indicated) at $5 \mathrm{~h}$ after D-GalN/ LPS challenge. WT mice and Per1 ${ }^{-1-}$ mice were administered $3 \mu \mathrm{g} / \mathrm{kg}$ body weight LPS intraperitoneally in combination with $200 \mathrm{mg} / \mathrm{kg}$ body weight D-GalN or PBS as the control. (d) Serum activities of ALT and AST were measured $5 \mathrm{~h}$ after D-GalN/LPS challenge. (e) H\&E staining of representative liver samples is shown. Experiments were repeated independently at least three times with consistent results. In each independent repeat, $n \geq 5$ ( $n$, number of samples in each group). ${ }^{*} P<0.05$, D-GalN/LPS group versus control group; ${ }^{\#} P<0.05$, Per1 $^{-1-}$ group versus WT group. Scale bar, $200 \mu \mathrm{m}$

Per1 deficiency increases hepatic Ccr2 expression and enhances hepatic macrophage migration. The increased number of KCs could also be due to enhanced monocyte/ macrophage recruitment to the liver. FACS analysis revealed a decrease in total $\mathrm{CD}_{115^{+}}$circulating monocytes in the peripheral blood of $\mathrm{Per1}^{-1-}$ mice. The relative number of
$\mathrm{CD}_{115^{+}} \mathrm{CD}_{11 \mathrm{~b}^{+}}$monocytes was also decreased in Per1 ${ }^{-1-}$ mice (Figure 4a). This observation implies that hepatic macrophage recruitment is enhanced in $\mathrm{Per}^{-1-}$ mice. It was suggested previously that CCR2/MCP-1 chemotaxis is responsible for the mobilization and subsequent trafficking of monocytes/macrophages to the liver. ${ }^{6-8}$ We have shown that 

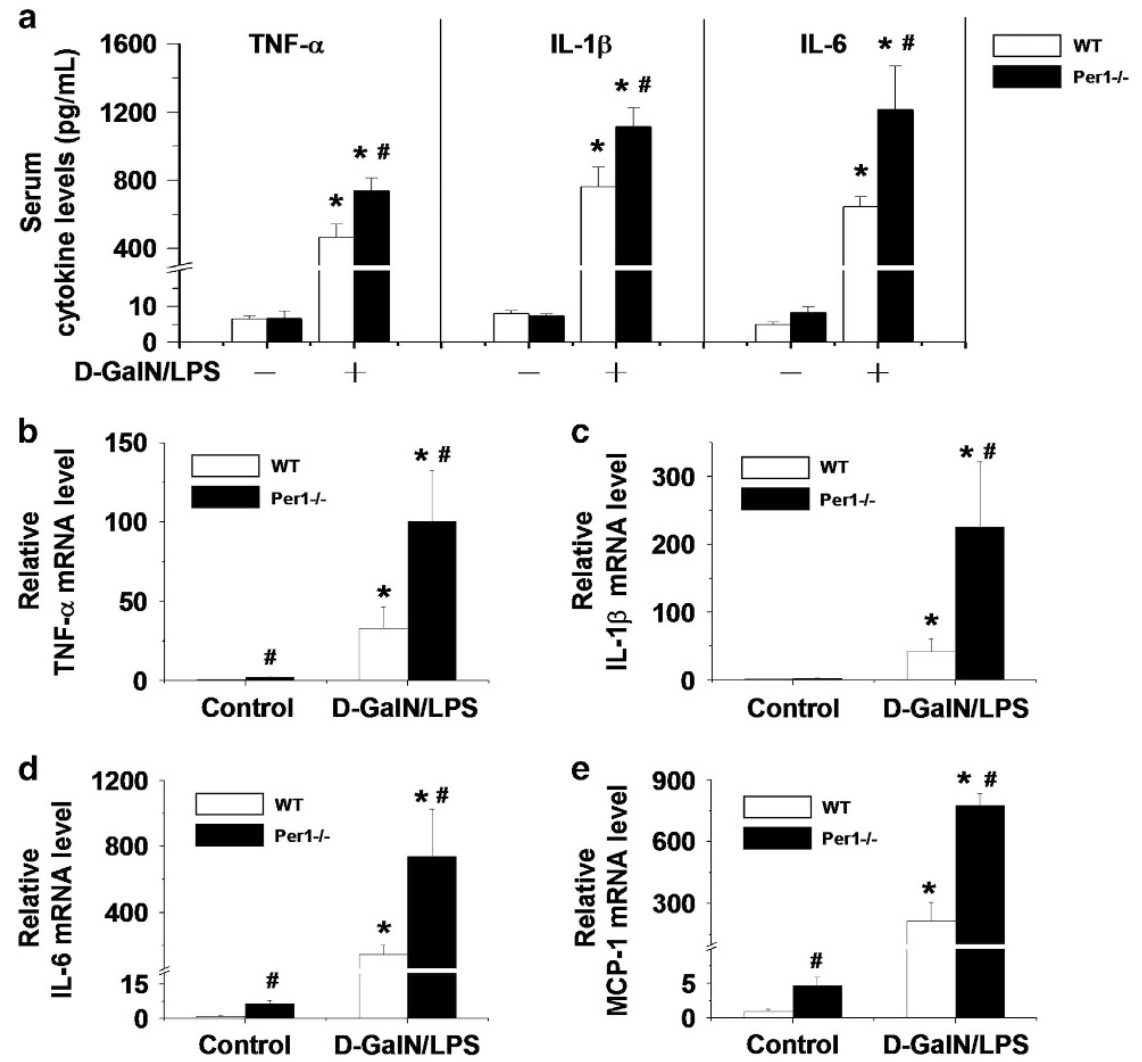

Figure 2 Per1 deficiency increases the expression of pro-inflammatory cytokines in the liver. Sera and livers of both WT and Per1 $1^{-1-}$ mice were harvested $5 \mathrm{~h}$ after i.p. injection of PBS or $5 \mu \mathrm{g} / \mathrm{kg}$ LPS and $500 \mathrm{mg} / \mathrm{kg}$ D-GalN. (a) Serum TNF- $\alpha$, IL- $1 \beta$ and IL- 6 were measured by ELISA. (b-e) The hepatic mRNA levels of TNF- $\alpha$, IL- $1 \beta$, IL- 6 and MCP-1 were measured by quantitative RT-PCR. Experiments were repeated independently at least three times with consistent results. In each independent repeat, $n=5$; ${ }^{*} P<0.05$, D-GalN/LPS group versus control group; ${ }^{\#} P<0.05, P e r 1^{-1-}$ group versus WT group

hepatic MCP-1 expression is significantly upregulated in $\mathrm{Per1}^{-1-}$ mice (Figure 2e). Similar MCP-1 mRNA levels between WT and Per1-deficient peritoneal macrophages suggest that the elevated hepatic MCP-1 expression in $\mathrm{Per}^{-1-}$ mice is due to the increased number of macrophages in the liver (Supplementary Figure S1D). Hepatic levels of Ccr2 were also significantly elevated in $\mathrm{Per1}^{-1-}$ mice (Figure 4b). Per1 deficiency increased the gene expression of Ccr2 in peritoneal macrophages (Figure 4c), and Ccr2 expression was markedly lower in RAW264.7 cells transfected with Per1 (Figure 4d). Next, a cell chemotaxis assay was performed on the peritoneal macrophages isolated from WT and Per1 ${ }^{-1-}$ mice. We found that macrophage chemotaxis was significantly induced by MCP-1 stimulation. Macrophages lacking Per1 exhibited higher chemotactic activity than WT macrophages (Figure 4e).

Deletion of Ccr2 rescues D-GaIN/LPS-induced liver injury in $\mathrm{Per1}^{-1-}$ mice by reducing hepatic macrophage recruitment. To further confirm the association between upregulation of Ccr2 and elevated susceptibility to D-GalN/ LPS in Per1 ${ }^{-1-}$ mice, we generated $\mathrm{Per}^{-1-} \mathrm{Ccr}^{-1-}$ (DKO) mice according to Mendel's law. WT, $P e r 1^{-1-}$ and DKO mice were injected with $5 \mu \mathrm{g} / \mathrm{kg}$ LPS and $500 \mathrm{mg} / \mathrm{kg}$ D-GalN. Deletion of Ccr2 significantly rescued D-GalN/LPS-induced liver injury in $\mathrm{Per}^{-I-}$ mice, as detected by reduced levels of serum ALT and AST in WT and DKO mice compared with $\mathrm{Per1}^{-1-}$ mice at $5 \mathrm{~h}$ after treatment (Figures $5 \mathrm{a}$ and b). Histological examinations of liver sections showed less severe confluent, hemorrhagic necrosis and hepatocyte apoptosis in WT and DKO mice compared with those in $\mathrm{Per1}^{-1-}$ mice (Figure 5c). We next determined the number of $\mathrm{KCs}$ in mice with different genotypes. Deletion of Ccr2 rescued the abnormal accumulation of KCs in $\mathrm{Per}^{-1-}$ mice, as determined by immunohistochemistry for F4/80 and CD68 (Figures $6 \mathrm{a}$ and $\mathrm{b}$ ). Flow cytometry analysis revealed a decrease in total hepatic $\mathrm{F} 4 / 80^{+}$cells in DKO mice, either under baseline conditions or after D-GalN/LPS treatment. A relative decrease in the number of $\mathrm{F} 4 / 80^{+} \mathrm{CD} 11 \mathrm{~b}^{+}$cells was also observed in DKO mice compared with $\mathrm{Per}^{-1-}$ mice. Although the proportions of both hepatic nonparenchymal subsets in DKO mice are similar to those in WT mice (Figure $6 \mathrm{c}$ ). These results indicated that deletion of $\mathrm{Ccr} 2$ rescues D-GalN/LPS-induced liver injury in $\mathrm{Per}^{-1-}$ mice by reducing hepatic macrophage recruitment.

Per1 mediates Ccr2 expression in macrophages through the PPAR- $\boldsymbol{\gamma}$ pathway. Previous studies reported that Ccr2 expression was repressed by signaling pathways involving PPAR $-\gamma$ activation. ${ }^{20-22}$ To investigate whether Per1 mediates Ccr2 expression in macrophages through the PPAR- $\gamma$ pathway, macrophages lacking or overexpressing Per1 were 
a
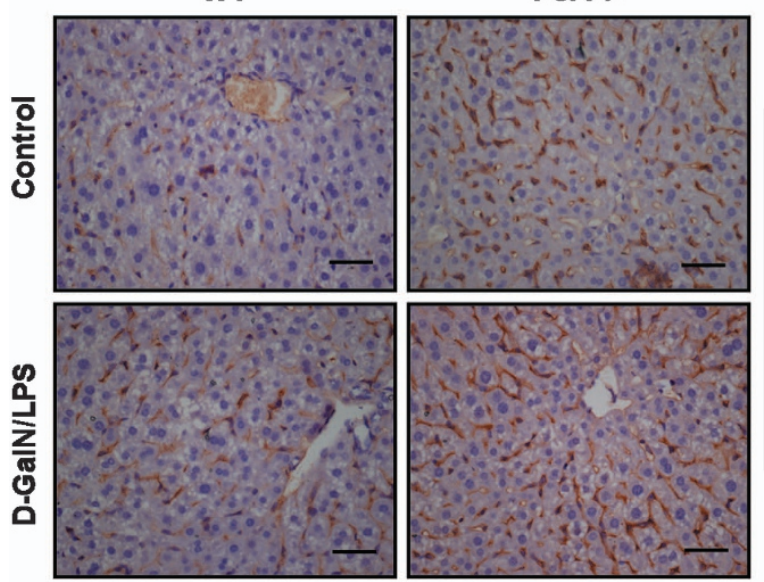

b
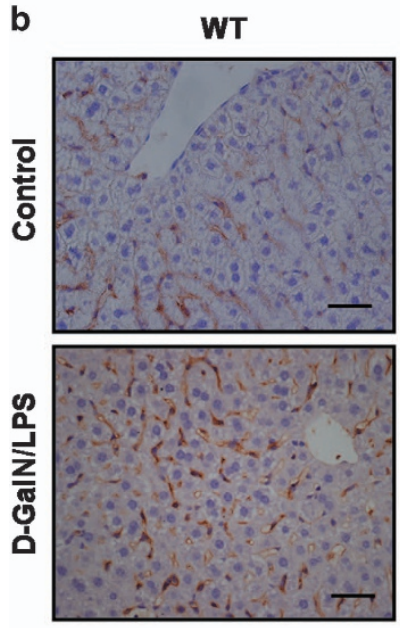

C

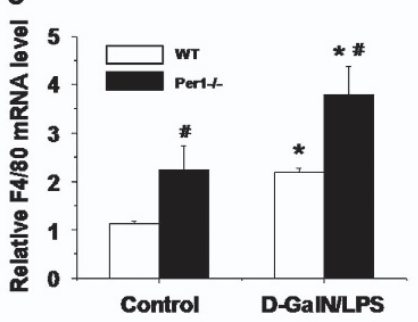

e

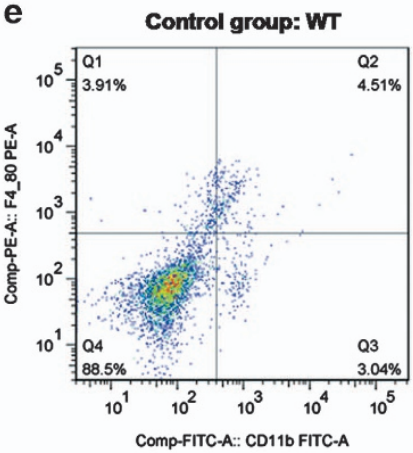

D-GaIN/LS group: WT
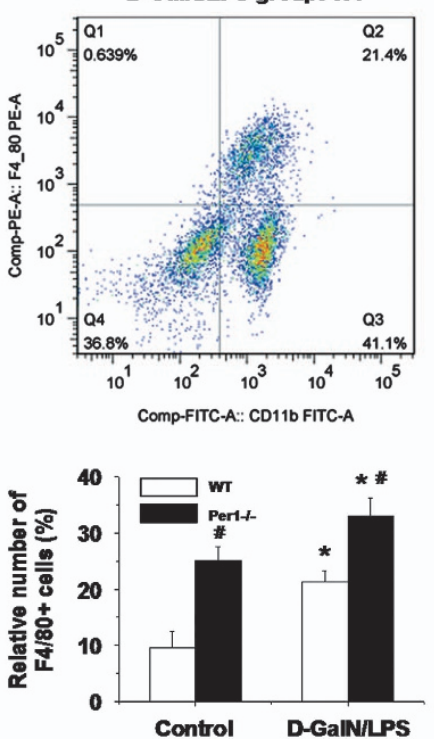
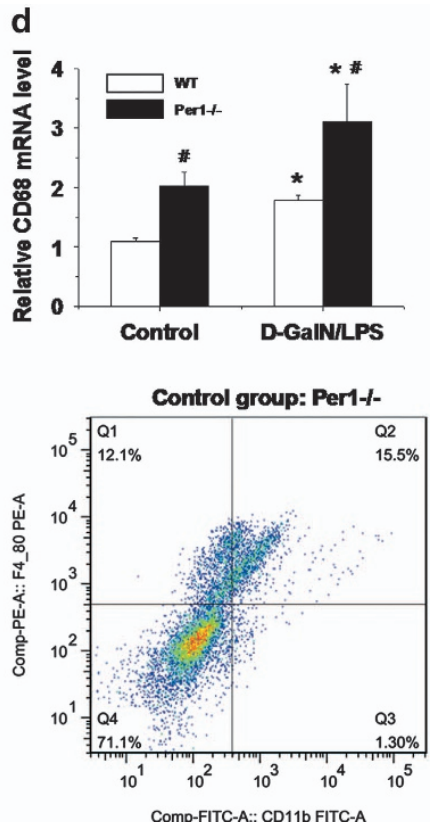

DGaINILPS group: Per1--
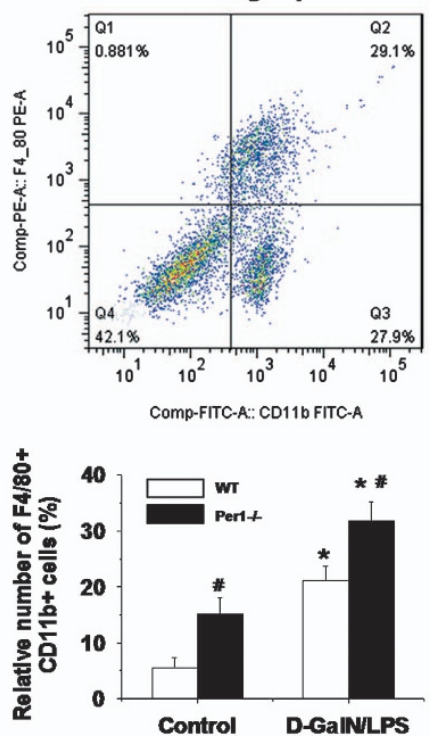

Figure 3 Increased number of macrophages in Per1-deficient livers. Liver tissues were harvested from WT and Per ${ }^{-1-}$ mice either under baseline conditions or at $3 \mathrm{~h}$ after D-GalN/LPS challenge. Representative immunohistochemical staining of livers was performed using antibodies against the specific macrophage markers F4/80 (a) and CD68 (b). Scale bar, $50 \mu \mathrm{m}$. The hepatic mRNA levels of F4/80 (c) and CD68 (d) were measured by quantitative RT-PCR. (e) Flow cytometric analysis of surface F4/80 and CD11b was used to determine the relative number of macrophages in the livers of mice. $n=5 ;{ }^{*} P<0.05$, D-GalN/LPS group versus control group; ${ }^{\#} P<0.05$, $P$ er $1^{-1-}$ group versus WT group

incubated in the presence or absence of $10 \mu \mathrm{M}$ GW9662, a specific irreversible PPAR $\gamma$ inhibitor. ${ }^{20-22}$ We found that GW9662 reversed either the upregulation of $C$ cr2 expression by Per1 deletion in peritoneal macrophages or the downregulation of Ccr2 expression by Per1 overexpression in RAW264.7 cells (Figures 7a and b), suggesting that Per1 regulates Ccr2 expression in macrophages through the PPAR- $\gamma$ pathway. Real-time RT-PCR and western blot analysis showed that Per1 had no significant effect on PPAR- $\gamma$ expression in macrophages (Figures 7c-e), implying that Per1 may mediate Ccr2 expression by influencing the activation of PPAR $-\gamma$.
PER1 interacts with PPAR- $\boldsymbol{\gamma}$. A ChIP mapping experiment indicated that both PER1 and PPAR- $\gamma$ bind specifically to only the $-180 /+16$-bp region of Ccr2 promoter (Figure $8 \mathrm{a}$ ), implying that PER1 protein may interact with PPAR $-\gamma$. Vectors expressing HA-tagged PER1 and PPAR- $\gamma 2$ were transfected into B6F10 cells. Immunoblots showed recovery of PPAR- $\gamma 2$ from B6F10 cells after immunoprecipitation with an anti-HA antibody. As expected, we discovered a physical association between PER1 and PPAR- $\gamma 2$ (Figure 8b). Addition of troglitazone (a synthetically specific PPAR- $\gamma$ ligand) ${ }^{23-25}$ or GW9662 did not significantly alter the association between these two proteins in immunoprecipitation assays (Figure $8 \mathrm{c}$ ). 
a
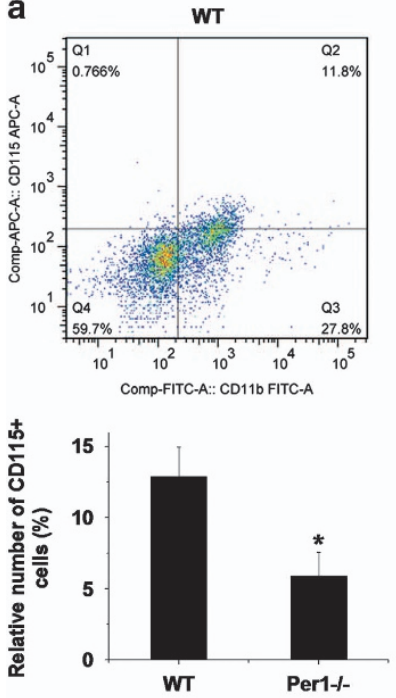

b

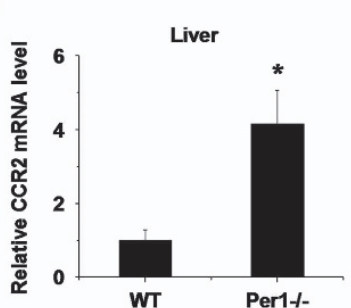

d

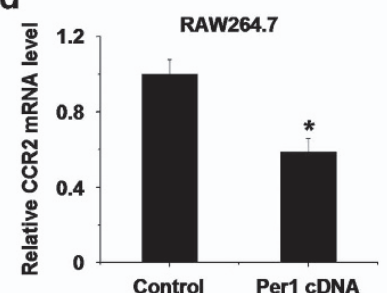

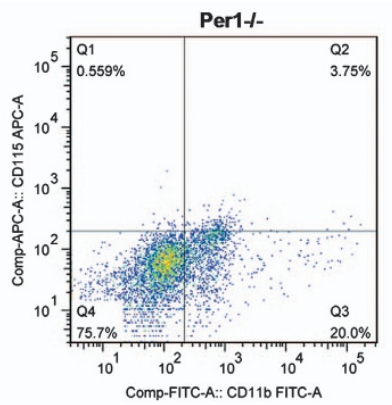

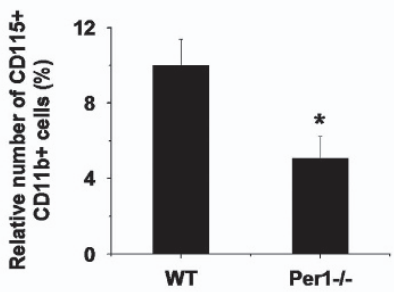

C

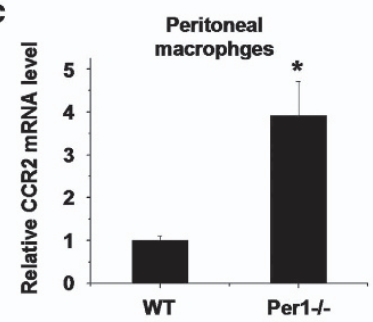

e

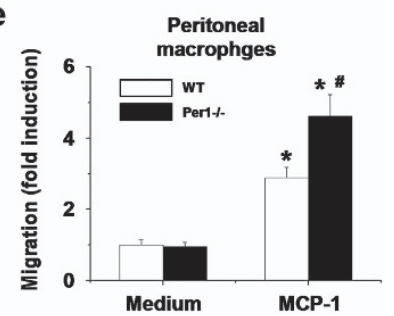

Figure 4 Per1 inhibits Ccr2 expression and macrophage migration. (a) Flow cytometry analysis of surface $\mathrm{CD} 115$ and $\mathrm{CD} 11 \mathrm{~b}$ was used to determine the relative numbers of monocytes in peripheral blood. Ccr2 expression was measured in the livers (b) and peritoneal macrophages (c). ${ }^{*} P<0.05, P e r 1^{-1-}$ group versus WT group. (d) RAW264.7 cells were transfected with the pCMV-Sport2 vector as the control or pCMV-Sport2 Per1, and the mRNA levels of Ccr2 were measured. ${ }^{*} P<0.05$, Per $1 \mathrm{cDNA}$ group versus control group. (e) Peritoneal macrophages isolated from WT or Per1 ${ }^{-1-}$ mice were placed in the upper chamber. Serum-free media containing MCP-1 $(50 \mathrm{ng} / \mathrm{ml})$ was placed in the lower chamber. Migration of the peritoneal macrophages into the lower chamber was determined $12 \mathrm{~h}$ after stimulation. ${ }^{*} P<0.05$, MCP-1 group versus medium group; ${ }^{\#} P<0.05$, Per1 ${ }^{-1-}$ group versus WT group. Experiments were repeated independently at least three times with consistent results. In each independent repeat, $n=5$

Finally, we used a series of HA-tagged deletion mutants of PPAR- $\gamma 2$ and investigated their interaction with PER1. Our results showed that amino acids $1-280$ of PPAR- $\gamma 2$ interact strongly with PER1, and a further deletion of 97 amino acids (1-183) abolished the ability of PPAR- $\gamma 2$ to bind to PER1 (Figure 8d), demonstrating that residues 183-280 of PPARY2 directly interact with PER1. However, residues 183-505, which also contain amino acids 183-280, could not bind to PER1. Despite not directly binding to PER1, residues 1-183

of PPAR- $\gamma 2$ may be indispensable to proper structure of PPAR- $\gamma 2$ and its association with PER1.

\section{Discussion}

Clock regulators appear to have an intimate role in the innate immune response aside from their role in circadian control. Published studies have clearly shown that leukocyte recruitment promotes LPS-induced lethality. ${ }^{26,27}$ Blood leukocyte numbers have long been known to exhibit circadian oscillations. ${ }^{14,15}$ Recent studies indicated that circadian rhythms modulate the innate immune system by regulating leukocyte recruitment. ${ }^{26}$ In this study, our results revealed that Per1 prevents widespread overactivation of the LPS-induced innate immune response by reducing excessive hepatic macrophage recruitment. Loss of Per1 significantly increased D-GalN/LPS-induced liver damage, which is essentially caused by high levels of pro-inflammatory cytokines, and resulted in elevation of mouse lethality. We demonstrated that the elevated cytokine production in $\mathrm{Per}^{-1-}$ mice is due to an increased number of macrophages in the liver. Per1 deletion resulted in excessive hepatic macrophage recruitment by upregulating Ccr2 expression through the PPAR $-\gamma$ pathway.

Earlier studies have demonstrated that the secretion of TNF- $a$ and its binding to TNFR-I are essential for both lethality and hepatic injury in LPS-induced hepatitis. ${ }^{28}$ Higher levels of LPS-induced hepatic TNF- $\alpha$ and other pro-inflammatory cytokines, such as IL-1 $\beta$ and IL-6, were observed in Per1 ${ }^{-1-}$ mice compared with WT mice, leading to more prominent liver damage and lethality in $P e r 1^{-1-}$ mice. It has been reported that the nuclear receptor Rev-Erba mediates selective circadian regulation of inflammatory cytokines. ${ }^{12}$ These reports inspired us to investigate whether Per1 directly regulates the expression of pro-inflammatory cytokines in the innate immune response to LPS. However, in vitro experiments revealed that Per1 has no effect on the expression of pro-inflammatory cytokines in mice macrophages, suggesting the higher hepatic levels of cytokines in $P e r 1^{-1-}$ mice may be due to the increased number of cells responding to LPS in the liver. Thus, loss of Per1 markedly increased the number of $\mathrm{KCs}$ in mice livers. $\mathrm{F} 4 / 80^{+} \mathrm{CD} 11 \mathrm{~b}^{+}$cells showed a strong capacity for the production of cytokines in response to LPS. ${ }^{19}$ Flow cytometry analysis also revealed an increase in the number of $\mathrm{F} 4 / 80^{+} \mathrm{CD} 11 \mathrm{~b}^{+}$cells in Per1 ${ }^{-1-}$ mice, either at baseline conditions or after D-GalN/LPS administration. This observation also well explained the elevation of hepatic cytokine expression in $\mathrm{Per}^{-1-}$ mice without D-GalN/LPS treatment.

Macrophages and their precursors, monocytes, have an important role during inflammatory injury. Monocytes migrate to the inflamed/necrotic area and subsequently differentiate into mature macrophages. ${ }^{29-31}$ Even in steady-state conditions, KCs are constantly replenished by blood monocytes. ${ }^{32}$ Peripheral blood monocytes are a heterogeneous population of circulating leukocytes. There are two functional subsets among murine blood monocytes: a short-lived CX3CR $1^{\text {lo }}$ $\mathrm{CCR}^{+} \mathrm{Gr}^{+}$subset that is actively recruited to inflamed tissues and a CX3CR $1^{\text {hi }} \mathrm{CCR}^{-} \mathrm{Gr}^{-}{ }^{-}$subset characterized by CX3CR1-dependent recruitment to non-inflamed tissues. ${ }^{33}$ In this study, the decline in $C \times 3 c r 1$ expression in Per1-deficient 
a

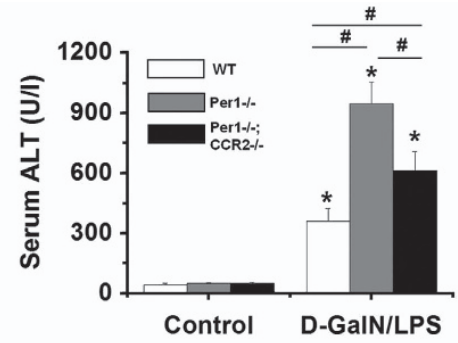

C
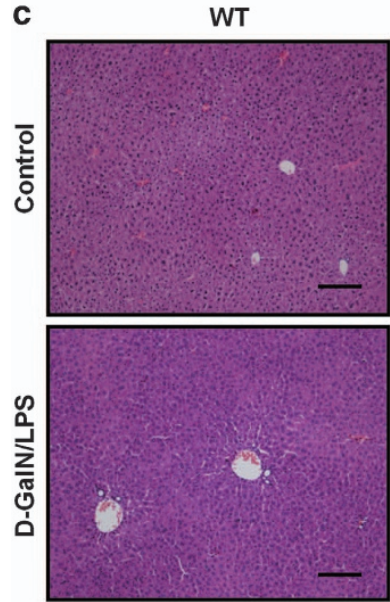

b

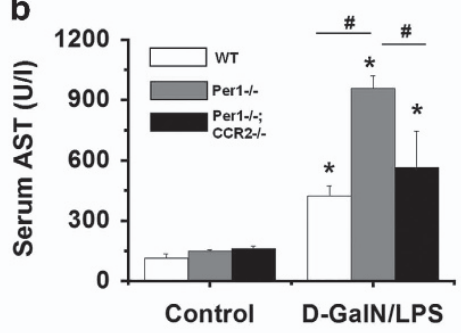

Per1-/-

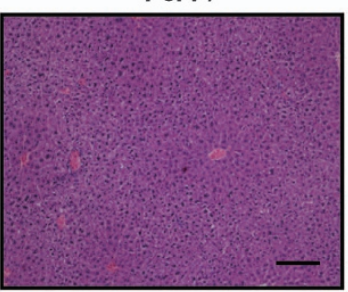

Per1-/-, CCR2-/-
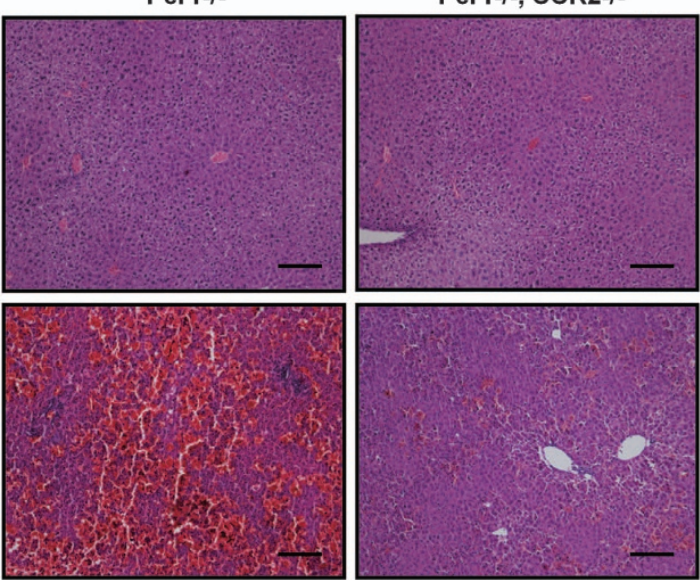

Figure 5 Deletion of Ccr2 rescues D-GalN/LPS-induced liver injury in Per1 ${ }^{-1-}$ mice. Per1 ${ }^{-1-}$ and Per1 ${ }^{-1-} ; \mathrm{Ccr}^{-1-}$ mice were administered $5 \mu \mathrm{g} / \mathrm{kg} \mathrm{LPS} \mathrm{and} 500 \mathrm{mg} / \mathrm{kg}$ D-GaIN intraperitoneally; PBS was administered as the control. Serum activities of ALT (a) and AST (b) were measured at $5 \mathrm{~h}$ after D-GalN/LPS challenge. (c) H\&E staining of representative liver samples is shown. Scale bar, $200 \mu \mathrm{m}$. Experiments were repeated independently at least three times with consistent results. In each independent repeat, $n=5$. ${ }^{*} P<0.05$, significant differences between control group and D-GalN/LPS group; ${ }^{\#} P<0.05$, significant differences between genotypes

a

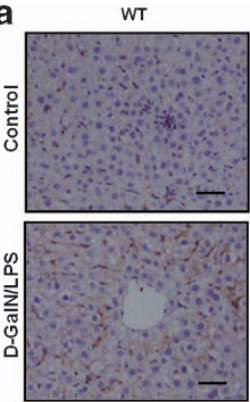

b

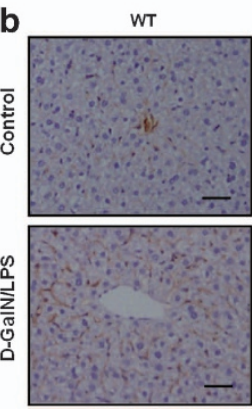

Per1\%

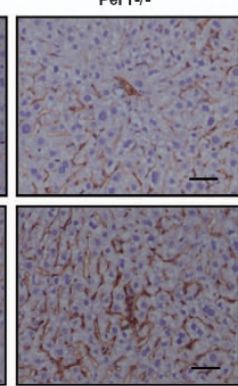

Per1\%

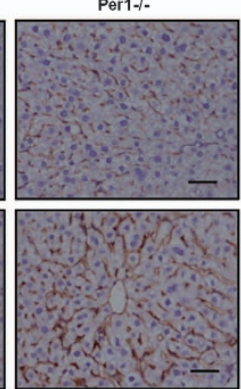

Per1-1-; CCR2-I-

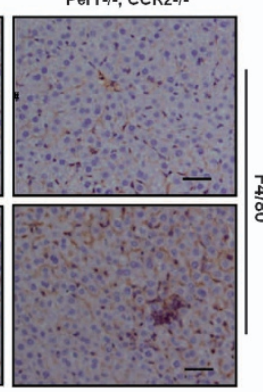

Per1--; CCR2-/-

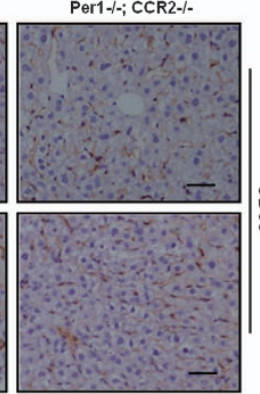

C
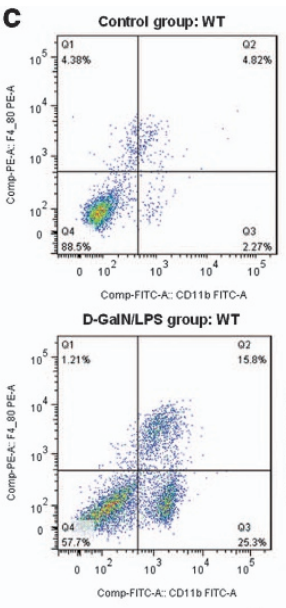

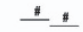

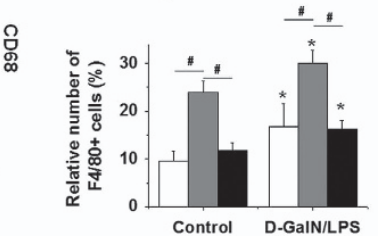

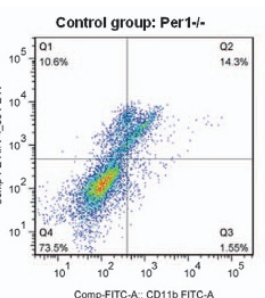

Control group: Per1-1\%; CCR2\%
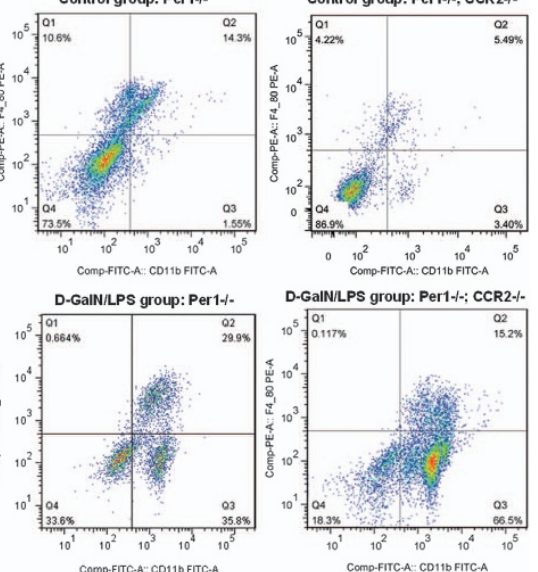

D-GaIN/LPS group: Per1 $1-;$ CCR2 $-\%$

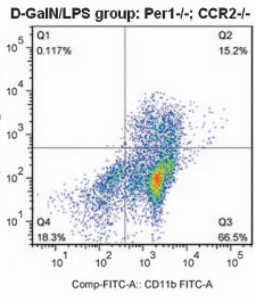

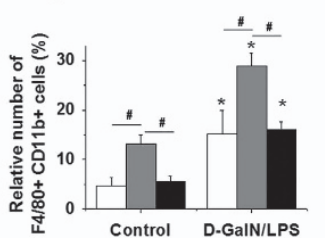

Figure 6 Deletion of $C c r 2$ reduces the number of macrophages in Per1-deficient livers. Liver tissues were harvested from Per1 ${ }^{-1-}$ and Per1 ${ }^{-1-}$; Ccr2 ${ }^{-1-}$ mice either under baseline conditions or at $3 \mathrm{~h}$ after $\mathrm{D}$-GalN/LPS challenge. Representative immunohistochemical staining of livers was performed using antibodies against F4/80 (a) and CD68 (b). Scale bar, $50 \mu \mathrm{m}$. (c) Flow cytometry analysis of surface F4/80 and CD11b was used to determine the relative number of macrophages in the livers of mice. $n=5$; ${ }^{*} P<0.05$, significant differences between control group and D-GalN/LPS group; ${ }^{\#} P<0.05$, significant differences between genotypes 

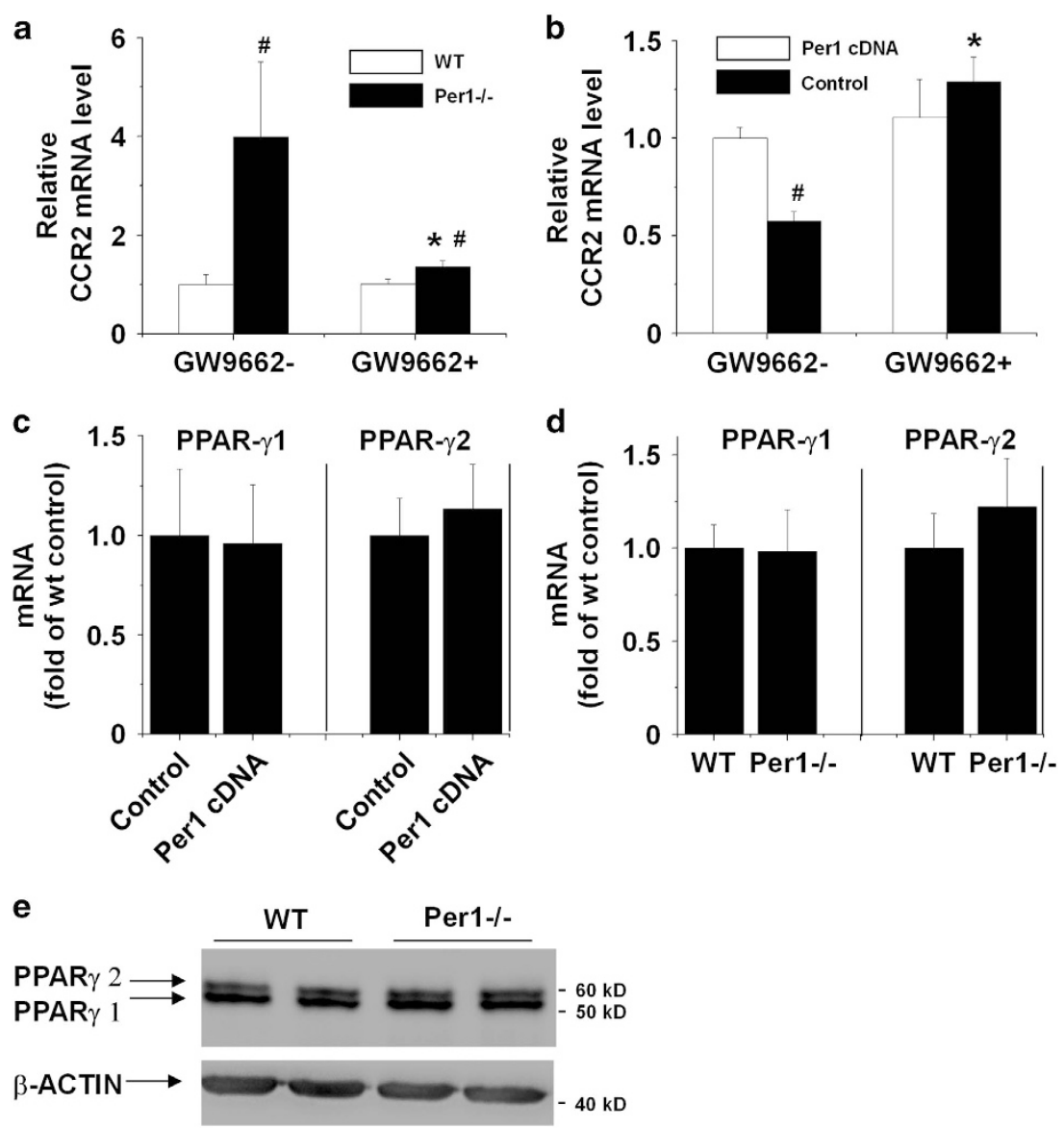

Figure 7 Per1 inhibits Ccr2 expression in macrophages through the PPAR- $\gamma$ pathway. After incubating for $3 \mathrm{~h}$ with or without $10 \mu \mathrm{M}$ GW9662, a specific and irreversible PPAR- $\gamma$ inhibitor, the mRNA levels of Ccr2 in peritoneal macrophages (a) and RAW264.7 cells transfected with vector alone or Per1 cDNA (b) were measured. $n=5$; ${ }^{*} P<0.05$, GW9662+ group versus GW9662- group; in $\mathbf{a},{ }^{\#} P<0.05$, Per $1^{-1}$ group versus WT group; in $\mathbf{b},{ }^{\#} P<0.05$, Per1 cDNA group versus control group. The mRNA levels of PPAR- $\gamma 1$ and PPAR- $\gamma 2$ in peritoneal macrophages (c) and RAW264.7 cells transfected with vector alone or Per1 cDNA (d) were measured by quantitative RT-PCR. $n=5$; in $\mathbf{c}$, ${ }^{*} P<0.05$, Per $^{-1-}$ group versus WT group; in $\mathbf{d},{ }^{*} P<0.05$, Per1 cDNA group versus control group. (e) Western blot analysis was performed on peritoneal macrophages using a PPAR- $\gamma$ antibody, and $\beta$-actin was used as an internal control

a

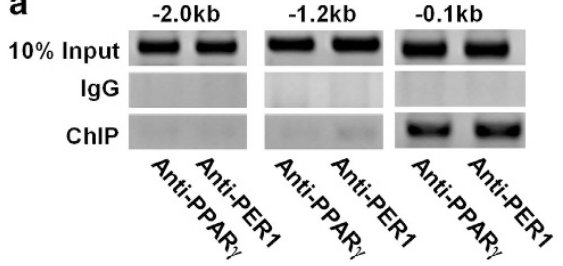

C

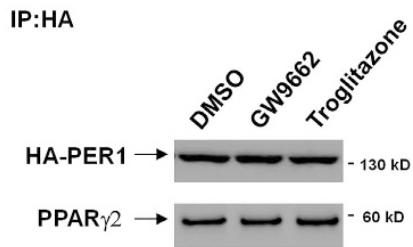

b

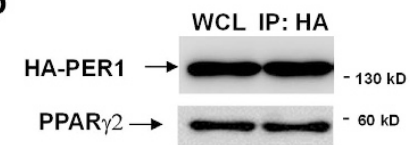

d

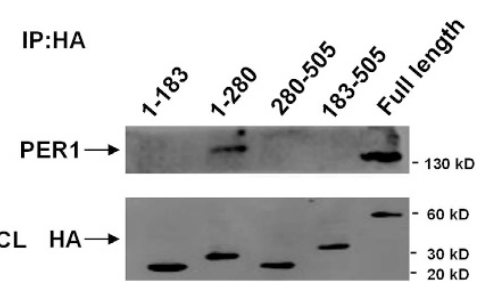

Figure 8 PER1 interacts with PPAR $-\gamma$. (a) Recruitment of PER1 or PPAR- $\gamma$ to the respective target region in the Ccr2 promoter was detected by a ChIP assay in peritoneal macrophages isolated from WT mice. (b and $\mathbf{c}$ ) Vectors expressing HA-tagged PER1 and PPAR- $\gamma 2$ were transfected into B6F10 cells. Immunoblots showed recovery of PPAR- $\gamma 2$ from B6F10 cells after immunoprecipitation with an anti-HA antibody. In c, GW9662 $(10 \mu \mathrm{M})$ or troglitazone $(10 \mu \mathrm{M})$ was added $3 \mathrm{~h}$ before the cells were harvested. (d) B6F10 cells were transfected with vectors expressing the corresponding HA-tagged fragments of PPAR- $\gamma 2$ and a vector expressing PER1. Immunoblots showed recovery of PER1 from B6F10 cells after immunoprecipitation with an anti-HA antibody. WCL, whole-cell lysate; IP, immunoprecipitated 
monocytes/macrophages could not directly contribute to the increased number of $\mathrm{KCs}$ in $\mathrm{Per1}^{-/-}$mice (data not shown). Previous studies demonstrated that $\mathrm{Ccr}^{-1-}$ mice exhibit decreased macrophage infiltration following acetaminopheninduced liver injury, ${ }^{34}$ indicating that MCP-1/CCR2 signaling is essential for monocyte migration to the injured liver. Increasing experimental evidence suggests that the chemokine receptor Ccr2 regulates monocyte entry into inflamed tissue, mainly indirectly, by promoting the egress of monocytes from the bone marrow into the circulation. ${ }^{6-8}$ In this study, we demonstrated that the expression of Ccr2 is significantly inhibited by Per1. MCP-1/CCR2 chemotaxis activity was enhanced in Per1-deficient macrophages. Deletion of Ccr2 reduced the number of $\mathrm{KCs}$ in $P e r 1^{-1-}$ mice. D-GalN/LPSinduced severe liver damage in $P e r 1^{-1-}$ mice was also ameliorated by $C$ cr2 deletion. These results further confirmed that the increased number of KCs in $P e r 1^{-1-}$ mice is due to the elevation of Ccr2 expression. The increase in the number of KCs in intact $\mathrm{Per1}^{-/-}$mice implied that CCR2 may also participate in the replenishment of KCs in $\mathrm{Per1}^{-1-}$ mice under steady-state conditions. Although it has been reported that Per1 has an important role in the cell cycle and apoptosis in cancer cells, ${ }^{26}$ the increase in KCs may also be attributed to the influence of Per1 on proliferation and/or apoptosis in macrophages. Here, we showed that Per1 alters neither the cell cycle nor apoptosis in macrophages.

Ccr2 gene expression is regulated by several signaling pathways, including calcineurin/NFAT, ${ }^{35} \mathrm{C} / \mathrm{EBPa}^{36}$ and PPAR $-\gamma .{ }^{20-22}$ It has been reported that activation of macrophage PPAR $-\gamma$ results in alterations of chemokine receptors such that CCR2 is inactivated and CX3CR1 is activated, resulting in cessation of CCR2-dependent migration and activation of CX3CR1-dependent anchorage to coronary artery smooth muscle cells. ${ }^{22}$ As Per1 was found to have opposite roles in Ccr2 and $\mathrm{Cx} 3 \mathrm{cr} 1$ expression (data not shown) in macrophages, we postulated that Per1 may suppress Ccr2 expression through the PPAR- $\gamma$ pathway. Our results indicated that the effect of Per1 on Ccr2 expression was reversed by the synthetic PPAR- $\gamma$ antagonist GW9662, which strongly supports our hypothesis.

The ChIP assay clearly showed that PER1 protein and PPAR $-\gamma$ bound specifically to only the $-180 /+16$-bp region of the Ccr2 promoter. In contrast to transcriptional activation, trans-repression does not involve binding to typical receptorspecific response elements; however, PPAR- $\gamma$ and transcription factors bind each other via protein-protein interactions, thus modulating their transcriptional activity. ${ }^{37,38}$ No potential typical PPAR- $\gamma$ DNA-binding site was identified in the -180 / +16 -bp region of the Ccr2 promoter, indicating that PPAR- $\gamma$ represses the transcription of Ccr2 by interacting with transcription factors. According to previous studies, ${ }^{35,36}$ NFAT and $\mathrm{C} / \mathrm{EBP}$ a can promote the transcription of $\mathrm{Ccr}$, and their binding sites in the Ccr2 promoter overlap with this PPAR- $\gamma$ binding region. Therefore, we speculated that PPAR $-\gamma$ may interact with one of these transcription factors and thus indirectly bind to the Ccr2 promoter. Further studies are required to support this hypothesis. mPERs have been reported to directly bind to nuclear receptors; however, they do not directly bind to DNA. ${ }^{39}$ PER2 has been reported to interact with the $\beta$-subunit of casein kinase $2,{ }^{40}$ glycogen synthase kinase $3 \beta,{ }^{41}$ REV-ERB and possibly other nuclear receptors. ${ }^{39-43}$ PER3 interacts with PPAR- $\gamma$ via an $\mathrm{N}$-terminal region including both $P A S$ domains and a preceding predicted helix-loop-helix motif. ${ }^{44}$ The recruitment of PER1 to the PPAR$\gamma$ binding region in the Ccr2 promoter implied that PER1 may bind to PPAR $-\gamma$ and stabilize the association between PPAR- $\gamma$ and the transcription factor on the Ccr2 promoter. In this study, co-immunoprecipitation assays revealed a physical association between PER1 and PPAR- $\gamma$. The addition of troglitazone or GW9662 did not significantly alter the association between these two proteins, indicating that PER1 binds to PPAR- $\gamma$ in a ligand-independent manner. Further investigation revealed that PPAR $-\gamma$ utilizes part of its DNA-binding and hinge domains (183-280), but not its ligand-binding domain (310-505), to bind PER1. This result further confirmed that the association between PER1 and PPAR- $\gamma$ is ligand independent. Overall, the evidence indicates that PPAR $-\gamma$ has an inhibitory effect on several pro-inflammatory cytokines via interaction with transcription factors such as NF-kB, AP-1 and STAT ${ }^{38}$ In this article, we showed that Per1 suppresses Ccr2 expression through the PPAR- $\gamma$ pathway but has no effect on the expression of cytokines in macrophages, suggesting that Per1 does not participate in the association between PPAR- $\gamma$ and transcription factors that functionally promote the transcription of these pro-inflammatory cytokines.

In summary, PER1 bound to PPAR- $\gamma$ and stabilized the association between PPAR- $\gamma$ and the transcription factor on the Ccr2 promoter. Deletion of Per1 alleviated the inhibitory effect of PPAR- $\gamma$ on Ccr2 expression, resulting in enhanced macrophage recruitment into the liver. The increased number of KCs caused elevation of cytokine production in D-GalN/ LPS-induced liver failure. Thus, the circadian gene Per1 could protect the liver from inflammatory damage by minimizing the KC-mediated immune response.

\section{Materials and Methods}

Animals. Per1 $1^{-1-}$ mice ${ }^{45}$ were obtained from Dr. CC Lee at Baylor College of Medicine, Houston, TX, USA. Ccr2-1- mice were obtained from Jackson Lab (Bar Harbor, ME, USA). The Per1 ${ }^{-1-}$; $\mathrm{Ccr}^{-1-}$ (DKO) mice were generated at the expected Mendelian ratios and developed normally. All of the animals were backcrossed for at least five generations before the first pilot study to ensure a largely homogenous C57BL/6J background. Male WT C57BL/6J mice and gene knockout mice at 8-10 weeks of age were used in this work. The animals were maintained in cycles of $12 \mathrm{~h}$ of light and $12 \mathrm{~h}$ of darkness with free access to food and water ad libitum. All animal care and use procedures were in accordance with the guidelines of the Institutional Animal Care and Use Committee at Nanjing University of Science and Technology.

Endotoxin-induced fulminant hepatitis model. Fulminant hepatitis in mice was established by intraperitoneal injection of LPS $(5 \mu \mathrm{g} / \mathrm{kg}$ body weight; Sigma-Aldrich, St. Louis, MO, USA) and D-GalN (500 mg/kg body weight; SigmaAldrich). To determine the survival rate, the animals were monitored continuously after LPS/D-GalN injection until their death. For assessment of liver damage, the animals were killed $5 \mathrm{~h}$ after treatment with this dose to obtain blood and liver tissue.

To induce non-lethal liver inflammation, mice were intraperitoneally injected with LPS ( $3 \mu \mathrm{g} / \mathrm{kg}$ body weight) and D-GalN (200 mg/kg body weight). Blood and liver samples were collected $5 \mathrm{~h}$ after treatment.

Serum aminotransferase activity and ELISA. Serum AST and ALT activities were measured using an AU2700 automatic biochemical analyzer (Olympus, Tokyo, Japan). Serum TNF- $\alpha, \mathrm{IL}-1 \beta$ and IL- 6 levels were determined using enzyme-linked immunosorbent assay (ELISA) kits (Boster Biological Technology Ltd, Wuhan, China) according to the manufacturer's protocol. 
Antibody. For immunohistochemical staining, purified antibodies were obtained from Abcam (Shanghai, China) and eBioscience (San Diego, CA, USA) (anti-mouse CD68, Abcam, cat no. ab955; anti-mouse F4/80, eBioscience, cat no. 14-4801). Antibodies for flow cytometry analysis were obtained from eBioscience and $\mathrm{BD}$ Biosciences (San Jose, CA, USA) (anti-mouse F4/80, PE-conjugated, eBioscience, cat no. 12-4801; anti-mouse CD11b, FITC- conjugated, BD Biosciences, cat no. 557396; anti-mouse CD115, APC-conjugated, eBioscience, cat no. 17-1152). Antibodies for western blots and immunoprecipitation assays were obtained from Sigma-Aldrich, Cell Signaling Technology (Shanghai, China), Abcam and Bioworld Technology (Nanjing, China) (anti-HA, Sigma-Aldrich, cat no. H3663; anti-mouse PPAR $\gamma$, Cell Signaling Technology, cat no. 2430; anti-mouse PER1, Abcam, cat no. ab3443; anti-mouse $\beta$-actin, Bioworld Technology, cat no. AP0060).

Histological analysis. Liver tissue was fixed in 10\% phosphate-buffered formalin overnight, embedded in paraffin and cut into $4-\mu \mathrm{m}$ sections. The sections were stained with hematoxylin and eosin (H\&E). CD68 and F4/80 were used as immunohistochemical markers for KCs in the liver as described previously. ${ }^{46}$

Cell culture and treatment. Peritoneal macrophages were isolated from mice by peritoneal lavage 4 days after injection of $2 \mathrm{ml}$ of $3 \%$ thioglycolate as described previously. ${ }^{47}$ Peritoneal macrophages and RAW264.7 cells were maintained in RPMI-1640 supplemented with 10\% low-endotoxin FBS and stimulated with LPS $(1 \mu \mathrm{g} / \mathrm{ml})$ for the indicated time periods.

RNA extraction and quantitative real-time PCR. Total RNA was extracted from the samples with Trizol (Invitrogen, Carlsbad, CA, USA) according to the manufacturer's instructions. The reverse transcription reaction was carried out using a reverse transcriptase kit (Invitrogen) according to the manufacturer's protocol. Real-time PCR was performed, and the products were detected using the ABI 7300 Detection System with SYBR Green dye (Toyobo, Osaka, Japan). The expression level of glyceraldehyde-3-phosphate dehydrogenase was simultaneously quantified as an internal standard control. Gene expression in monocytes/ macrophages was normalized against B2M and TBP as previously described. ${ }^{48}$ The sequences of all primers used for quantitative RT-PCR are shown in Supplementary Table S1.

Flow cytometry. For flow cytometry experiments, hepatic inflammatory cells and peripheral blood mononuclear cells (PBMCs) were prepared as described previously. ${ }^{29}$ Hepatic inflammatory cells were stained with fluorescently labeled antibodies against F4/80 and CD11b. PBMCs were incubated with fluorescently labeled antibodies against CD115 and CD11b. Flow cytometric analysis was performed by using a FACScan flow cytometer (BD Biosciences) at Nanjing Medical University.

For cell cycle analysis, cells in the G0/G1, S and G2/M phases of the cell cycle were identified using Vybrant Dye Cycle violet stain (Invitrogen) according to the manufacturer's protocol. The proportion of apoptotic cells was measured using a FACScan flow cytometer according to the instructions provided in the Annexin V/PI kit (Invitrogen).

Cell chemotaxis assay. The cell chemotaxis assay was performed as previously described. ${ }^{49}$ Peritoneal macrophages were placed in the upper chambers of the transwell $\left(5 \times 10^{4}\right.$ cells per well) and exposed to medium or MCP-1 $(50 \mathrm{ng} / \mathrm{ml}$, R\&D Systems, Shanghai, China) in the lower chamber. After a 12-h incubation, the number of migrated cells was determined by blinded observers, who counted 10 microscopic fields per well.

Western blot analysis. Proteins were extracted following the procedure described previously. ${ }^{50}$ The proteins were separated by SDS-PAGE on $8-12 \%$ polyacrylamide gels and subsequently electrically transferred to a PVDF membrane. After blocking with $5 \%(\mathrm{w} / \mathrm{v}) \mathrm{BSA}$ in TBST at room temperature for $1 \mathrm{~h}$, the membranes were then incubated with an appropriate specific primary antibody (antiHA, $1: 2000$; anti-PPAR- $\gamma, 1: 1000$; anti-PER1, $1: 200$; anti- $\beta$-actin, $1: 1000)$ at $4{ }^{\circ} \mathrm{C}$ overnight, followed by incubation with an HRP-conjugated secondary antibody $(1: 10000)$. Detection was performed using an enhanced chemiluminescence kit (Thermo Scientific, Hudson, NH, USA).

Chromatin immunoprecipitation assays. The ChIP assay was performed as described previously with slight modifications. ${ }^{51}$ RAW264.7 cells were plated in 100-mm dishes and stimulated with LPS for $1 \mathrm{~h}$. Cross-linked chromatin was immunoprecipitated with $5 \mu \mathrm{g}$ of a specific antibody (anti-PPAR- $\gamma$;
anti-PER1) or negative control rabbit IgG (Millipore, Billerica, MA, USA) at $4{ }^{\circ} \mathrm{C}$ overnight. Immunoprecipitated DNA was then used as a template for PCR. The sequences of all primers used for ChIP-PCRs are listed in Supplementary Table S2.

Co-immunoprecipitation. For co-immunoprecipitation, B6F10 cells were transfected with the indicated plasmids using Lipofectamine 2000 Transfection Reagent (Invitrogen) in 10-cm dishes. Co-immunoprecipitation was performed as described previously. ${ }^{52}$ Briefly, cells were lysed with a solution containing $10 \mathrm{mM}$ Tris- $\mathrm{HCl}(\mathrm{pH} 8), 420 \mathrm{mM} \mathrm{NaCl}, 1 \mathrm{mM}$ EDTA and $0.5 \%$ NP-40 with protease inhibitor cocktail (Boster Biological Technology Ltd). To prepare the immunoprecipitates, we incubated the cell lysates with an anti-HA monoclonal antibody (Sigma-Aldrich) overnight at $4{ }^{\circ} \mathrm{C}$ followed by incubation with Protein A-Sepharose 4B (Invitrogen). The immunoprecipitates were washed five times with wash buffer containing $10 \mathrm{mM}$ Tris-HCl pH 8, $100 \mathrm{mM} \mathrm{NaCl}, 1 \mathrm{mM}$ EDTA, 0.5\% NP-40 and 0.5\% Triton X-100 and subsequently boiled in SDS-PAGE loading buffer. The proteins were analyzed by western blotting as described above.

Statistical analysis. The statistical significance of lethality was analyzed using the Kaplan-Meier method. Groups of data are presented as mean \pm S.D. One-way analysis of variance followed by Dunnett's test or Student's $t$-test was used to determine the statistical significance of difference in measured parameters. Difference was considered significant at $P<0.05$.

\section{Conflict of Interest}

The authors declare no conflict of interest.

Acknowledgements. We thank Dr. CC Lee for providing Per1-deficient mice and the PCMV-Sport2 Per1 plasmid. This work was supported by the 973 program 2013CB945203, 2012CB517505 and NSFC 31471111.

1. Bernal W, Auzinger G, Dhawan A, Wendon J. Acute liver failure Lancet 2010; 376: 190-201.

2. Josephs MD, Bahjat FR, Fukuzuka K, Ksontini R, Solorzano CC, Edwards CK et al. Lipopolysaccharide and D-galactosamine-induced hepatic injury is mediated by TNF- $\alpha$ and not by Fas ligand. Am J Physiol Regul Integr Comp Physiol 2000; 278: R1196-R1201.

3. Schmöcker C, Weylandt KH, Kahlke L, Wang J, Lobeck H, Tiegs G et al. Omega-3 fatty acids alleviate chemically induced acute hepatitis by suppression of cytokines. Hepatology 2007; 45: 864-869.

4. Antoniades CG, Quaglia A, Taams LS, Mitry RR, Hussain M, Abeles R et al. Source and characterization of hepatic macrophages in acetaminophen-induced acute liver failure in humans. Hepatology 2012; 56: 735-746.

5. Antoniades CG, Berry PA, Wendon JA, Vergani D. The importance of immune dysfunction in determining outcome in acute liver failure. J Hepatol 2008; 49: 845-861.

6. Serbina NV, Jia T, Hohl TM, Pamer EG. Monocyte-mediated defense against microbial pathogens. Annu Rev Immunol 2008; 26: 421.

7. Serbina NV, Pamer EG. Monocyte emigration from bone marrow during bacterial infection requires signals mediated by chemokine receptor CCR2. Nat Immunol 2006; 7: 311-317.

8. Karlmark KR, Weiskirchen R, Zimmermann HW, Gassler N, Ginhoux F, Weber C et al. Hepatic recruitment of the inflammatory Gr1+ monocyte subset upon liver injury promotes hepatic fibrosis. Hepatology 2009; 50: 261-274.

9. Reppert SM, Weaver DR. Coordination of circadian timing in mammals. Nature 2002; 418: 935-941.

10. Schibler U. Circadian time keeping: the daily ups and downs of genes, cells, and organisms. Prog Brain Res 2006; 153: 271-282.

11. Liu J, Mankani G, Shi X, Meyer M, Cunningham-Runddles S, Ma X et al. The circadian clock Period 2 gene regulates gamma interferon production of NK cells in host response to lipopolysaccharide-induced endotoxic shock. Infect Immun 2006; 74: 4750-4756.

12. Gibbs JE, Blaikley J, Beesley S, Matthews L, Simpson KD, Boyce SH et al. The nuclear receptor REV-ERB $\alpha$ mediates circadian regulation of innate immunity through selective regulation of inflammatory cytokines. Proc Natl Acad Sci USA 2012; 109: 582-587.

13. Silver AC, Arjona A, Walker WE, Fikrig E. The circadian clock controls toll-like receptor 9-mediated innate and adaptive immunity. Immunity 2012; 36: 251-261.

14. Haus E, Smolensky MH. Biologic rhythms in the immune system. Chronobiol Int 1999; 16: $581-622$.

15. Born J, Lange T, Hansen K, Mölle M, Fehm H-L. Effects of sleep and circadian rhythm on human circulating immune cells. J Immunol 1997; 158: 4454-4464.

16. Keller M, Mazuch J, Abraham U, Eom GD, Herzog ED, Volk H-D et al. A circadian clock in macrophages controls inflammatory immune responses. Proceed Natl Acad Sci USA 2009; 106: 21407-21412.

17. Forwood JK, Thakur AS, Guncar G, Marfori M, Mouradov D, Meng W et al. Structural basis for recruitment of tandem hotdog domains in acyl-CoA thioesterase 7 and its role in inflammation. Proc Natl Acad Sci USA 2007; 104: 10382-10387. 
18. Kinoshita M, Uchida T, Sato A, Nakashima M, Nakashima H, Shono S et al. Characterization of two F4/80-positive Kupffer cell subsets by their function and phenotype in mice. $J$ Hepatol 2010; 53: 903-910.

19. Radi ZA, Koza-Taylor PH, Bell RR, Obert LA, Runnels HA, Beebe JS et al. Increased serum enzyme levels associated with kupffer cell reduction with no signs of hepatic or skeletal muscle injury. Am J Pathol 2011; 179: 240-247.

20. Chen Y, Green SR, Ho J, Li A, Almazan F, Quehenberger O. The mouse CCR2 gene is regulated by two promoters that are responsive to plasma cholesterol and peroxisome proliferator-activated receptor $\gamma$ ligands. Biochem Biophys Res Commun 2005; 332 : 188-193.

21. Han KH, Ryu J, Hong KH, Ko J, Pak YK, Kim J-B et al. HMG-CoA reductase inhibition reduces monocyte $\mathrm{CC}$ chemokine receptor 2 expression and monocyte chemoattractant protein-1-mediated monocyte recruitment in vivo. Circulation 2005; 111: 1439-1447.

22. Barlic J, Zhang Y, Foley JF, Murphy PM. Oxidized lipid-driven chemokine receptor switch, CCR2 to CX3CR1, mediates adhesion of human macrophages to coronary artery smooth muscle cells through a peroxisome proliferator-activated receptor $\gamma$-dependent pathway. Circulation 2006; 114: 807-819.

23. Ricote M, Li AC, Willson TM, Kelly CJ, Glass CK. The peroxisome proliferator-activated receptor-gamma is a negative regulator of macrophage activation. Nature 1998; 391: 79-82.

24. Jiang C, Ting AT, Seed B. PPAR-gamma agonists inhibit production of monocyte inflammatory cytokines. Nature 1998; 391: 82-86.

25. Marciano DP, Kuruvilla DS, Boregowda SV, Asteian A, Hughes TS, Garcia-Ordonez R et al. Pharmacological repression of PPARgamma promotes osteogenesis. Nat Commun 2015; 6: 7443.

26. Scheiermann C, Kunisaki Y, Lucas D, Chow A, Jang J-E, Zhang D et al. Adrenergic nerves govern circadian leukocyte recruitment to tissues. Immunity 2012; 37: 290-301.

27. Xu H, Gonzalo JA, St Pierre Y, Williams IR, Kupper TS, Cotran RS et al. Leukocytosis and resistance to septic shock in intercellular adhesion molecule 1-deficient mice. J Exp Med 1994; 180: 95-109.

28. Wang Y, Singh R, Lefkowitch JH, Rigoli RM, Czaja MJ. Tumor necrosis factor-induced toxic liver injury results from JNK2-dependent activation of caspase-8 and the mitochondrial death pathway. J Biol Chem 2006; 281: 15258-15267.

29. Ren X, Zhang Y, Snyder J, Cross ER, Shah TA, Kalin TV et al. Forkhead box M1 transcription factor is required for macrophage recruitment during liver repair. Mol Cell Biol 2010; 30: $5381-5393$.

30. Arnold L, Henry A, Poron F, Baba-Amer Y, Van Rooijen N, Plonquet A et al. Inflammatory monocytes recruited after skeletal muscle injury switch into antiinflammatory macrophages to support myogenesis. J Exp Med 2007; 204: 1057-1069.

31. Templeton SP, Kim TS, O'Malley K, PerIman S. Maturation and localization of macrophages and microglia during infection with a neurotropic murine coronavirus. Brain Pathol 2008; 18 40-51.

32. Klein I, Cornejo JC, Polakos NK, John B, Wuensch SA, Topham DJ et al. Kupffer cell heterogeneity: functional properties of bone marrow-derived and sessile hepatic macrophages. Blood 2007; 110: 4077-4085.

33. Geissmann F, Jung S, Littman DR. Blood monocytes consist of two principal subsets with distinct migratory properties. Immunity 2003; 19: 71-82.

34. Dambach DM, Watson LM, Gray KR, Durham SK, Laskin DL. Role of CCR2 in macrophage migration into the liver during acetaminophen-induced hepatotoxicity in the mouse. Hepatology 2002; 35: 1093-1103.

35. Jung $\mathrm{H}$, Miller RJ. Activation of the nuclear factor of activated T-cells (NFAT) mediates upregulation of CCR2 chemokine receptors in dorsal root ganglion (DRG) neurons: possible mechanism for activity-dependent transcription in DRG neurons in association with neuropathic pain. Mol Cell Neurosci 2008; 37: 170-177.

36. lida S, Watanabe-Fukunaga R, Nagata S, Fukunaga R. Essential role of C/EBP $\alpha$ in G-CSFinduced transcriptional activation and chromatin modification of myeloid-specific genes. Genes Cells 2008; 13: 313-327.
37. Ricote M, Glass CK. PPARs and molecular mechanisms of transrepression. Biochim Biophys Acta Mol Cell Biol Lipids 2007; 1771: 926-935.

38. Rigamonti E, Chinetti-Gbaguidi G, Staels B. Regulation of macrophage functions by PPAR- $\alpha$, PPAR- $\gamma$, and LXRs in mice and men. Arterioscler Thromb Vasc Biol 2008; 28 . 1050-1059.

39. Kucera N, Schmalen I, Hennig S, Öllinger R, Strauss HM, Grudziecki A et al. Unwinding the differences of the mammalian PERIOD clock proteins from crystal structure to cellular function. Proc Natl Acad Sci USA 2012; 109: 3311-3316.

40. Tsuchiya $Y$, Akashi M, Matsuda M, Goto K, Miyata Y, Node K et al. Involvement of the protein kinase CK2 in the regulation of mammalian circadian rhythms. Sci Signal 2009; 2 ra26-ra26.

41. litaka C, Miyazaki K, Akaike T, Ishida N. A role for glycogen synthase kinase- $3 \beta$ in the mammalian circadian clock. J Biol Chem 2005; 280: 29397-29402.

42. Schmutz I, Ripperger JA, Baeriswyl-Aebischer S, Albrecht U. The mammalian clock component PERIOD2 coordinates circadian output by interaction with nuclear receptors. Genes Dev 2010; 24: 345-357.

43. Maier B, Wendt S, Vanselow JT, Wallach T, Reischl S, Oehmke S et al. A large-scale functional RNAi screen reveals a role for CK2 in the mammalian circadian clock. Genes Dev 2009; 23: 708-718.

44. Costa MJ, So AY, Kaasik K, Krueger KC, Pillsbury ML, Fu Y-H et al. Circadian rhythm gene period 3 is an inhibitor of the adipocyte cell fate. J Biol Chem 2011; 286: 9063-9070.

45. Zheng B, Larkin DW, Albrecht U, Sun ZS, Sage M, Eichele G et al. The mPer2 gene encodes a functional component of the mammalian circadian clock. Nature 1999; 400: 169-173.

46. Stienstra R, Saudale F, Duval C, Keshtkar S, Groener JE, van Rooijen N et al. Kupffer cells promote hepatic steatosis via interleukin-1 $\beta$-dependent suppression of peroxisome proliferator-activated receptor $\alpha$ activity. Hepatology 2010; 51: 511-522.

47. Jiang W, Sun R, Wei H, Tian Z. Toll-like receptor 3 ligand attenuates LPS-induced liver injury by down-regulation of toll-like receptor 4 expression on macrophages. Proc Natl Acad Sci USA 2005; 102: 17077-17082.

48. Piehler AP, Grimholt RM, Øvstebø R, Berg JP. Gene expression results in lipopolysaccharide-stimulated monocytes depend significantly on the choice of reference genes. BMC Immunol 2010; 11: 21.

49. Seki E, De Minicis S, Inokuchi S, Taura K, Miyai K, Van Rooijen N et al. CCR2 promotes hepatic fibrosis in mice. Hepatology 2009; 50: 185-197.

50. Yang $\mathrm{P}$, Chen $\mathrm{P}$, Wang $\mathrm{T}$, Zhan $\mathrm{Y}$, Zhou $\mathrm{M}$, Xia $\mathrm{L}$ et al. Loss of $\mathrm{A} 1$ adenosine receptor attenuates alpha-naphthylisothiocyanate-induced cholestatic liver injury in mice. Toxicol Sci 2012; 131: 128-138.

51. Spencer VA, Sun J-M, Li L, Davie JR. Chromatin immunoprecipitation: a tool for studying histone acetylation and transcription factor binding. Methods 2003; 31: 67-75.

52. Pascual G, Fong AL, Ogawa S, Gamliel A, Li AC, Perissi V et al. A SUMOylation-dependent pathway mediates transrepression of inflammatory response genes by PPAR- $\gamma$. Nature 2005; 437: 759-763.

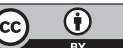

Cell Death and Disease is an open-access journal published by Nature Publishing Group. This work is licensed under a Creative Commons Attribution 4.0 International License. The images or other third party material in this article are included in the article's Creative Commons license, unless indicated otherwise in the credit line; if the material is not included under the Creative Commons license, users will need to obtain permission from the license holder to reproduce the material. To view a copy of this license, visit http://creativecommons.org/licenses/by/4.0/

Supplementary Information accompanies this paper on Cell Death and Disease website (http://www.nature.com/cddis) 